\title{
Galcanezumab in chronic migraine
}

\section{The randomized, double-blind, placebo-controlled REGAIN study}

Holland C. Detke, PhD, Peter J. Goadsby, MD, PhD, Shufang Wang, PhD, Deborah I. Friedman, MD, MPH, Katherine J. Selzler, PhD, and Sheena K. Aurora, MD

Neurology ${ }^{\circledR}$ 2018;91:e2211-e2221. doi:10.1212/WNL.0000000000006640

\section{Abstract}

\section{Objective}

To evaluate the efficacy and safety of galcanezumab, a humanized monoclonal antibody that selectively binds to calcitonin gene-related peptide, in the preventive treatment of chronic migraine.

\section{Methods}

A phase 3, randomized, double-blind, placebo-controlled study of LY2951742 in patients with chronic migraine (Evaluation of Galcanezumab in the Prevention of Chronic Migraine [REGAIN]) was a phase 3 study with a 3-month double-blind, placebo-controlled treatment phase and a 9-month open-label extension. Eligible patients 18 to 65 years of age with chronic migraine were randomized 2:1:1 to monthly subcutaneous injections of placebo $(\mathrm{n}=558)$, galcanezumab $120 \mathrm{mg}$ (with a 240-mg loading dose, $\mathrm{n}=278$ ), or galcanezumab $240 \mathrm{mg}(\mathrm{n}=$ 277). The primary endpoint was the overall mean change from baseline in the number of monthly migraine headache days (MHDs) during the 3-month double-blind treatment phase.

\section{Results}

Mean number of monthly MHDs at baseline was 19.4 for the total sample. Both galcanezumab dose groups demonstrated greater overall mean reduction in the number of monthly MHDs compared to placebo (placebo -2.7, galcanezumab $120 \mathrm{mg}-4.8$, galcanezumab $240 \mathrm{mg}-4.6$ ) $(p<0.001$ for each dose compared to placebo). There were no clinically meaningful differences between galcanezumab doses and placebo on any safety or tolerability outcome except for a higher incidence of treatment-emergent injection-site reaction $(p<0.01)$, injection-site erythema $(p<0.001)$, injection-site pruritus $(p<0.01)$, and sinusitis $(p<0.05)$ in the galcanezumab $240-\mathrm{mg}$ group relative to placebo.

\section{Conclusions}

Both doses of galcanezumab were superior to placebo in reducing the number of monthly MHDs. Galcanezumab appears efficacious, safe, and well tolerated for the preventive treatment of chronic migraine.

\section{ClinicalTrials.gov identifier \\ NCT02614261.}

\section{Classification of evidence}

This interventional study provides Class I evidence that galcanezumab is superior to placebo in the reduction of the number of monthly MHDs.

\author{
Correspondence \\ Dr. Detke \\ detkehc@lilly.com
}

\section{RELATED ARTICLE}

Lasmiditan is an effective acute treatment for migraine: A phase 3 randomized study

Page 1083

\section{MORE ONLINE}

\section{$\rightarrow$ Class of Evidence}

Criteria for rating therapeutic and diagnostic studies

NPub.org/coe 


\section{Glossary}

$\mathrm{ADA}=$ anti-drug antibodies; $\mathrm{AE}=$ adverse event $\mathbf{C M}=$ chronic migraine; $\mathrm{CGRP}=$ calcitonin gene-related peptide; $\mathrm{ePRO}=$ electronic patient-reported outcomes; ICHD = International Classification of Headache Disorders, 3rd edition, beta version; MHD = migraine headache day; MIDAS = Migraine Disability Assessment; MSQ = Migraine-Specific Quality of Life Questionnaire; PGI-S = Patient Global Impression of Severity of Illness; REGAIN = Evaluation of Galcanezumab in the Prevention of Chronic Migraine.

Chronic migraine $(\mathrm{CM})$ is a neurologic disease characterized by at least 15 headache days per month, of which at least 8 are migraine. ${ }^{1}$ Although less prevalent than episodic migraine, $\mathrm{CM}$ is associated with substantially greater headache-related disability, comorbid medical and psychiatric conditions, and health care resource use and poorer quality of life. ${ }^{2}$ Individuals with $\mathrm{CM}$ are at particularly high risk for headache associated with acute medication overuse, which may exacerbate the disease. ${ }^{3}$ Therefore, it is of critical importance to develop effective and well-tolerated migraine preventive treatments to reduce disability and to prevent disease progression.

Calcitonin gene-related peptide (CGRP) is a promising target for migraine prevention. ${ }^{4}$ Three previous monoclonal antibodies to CGRP or one of its receptors have been studied as preventive therapy for CM. Eptinezumab, ${ }^{5}$ fremanezumab, ${ }^{6}$ and erenumab ${ }^{7}$ have shown efficacy in either phase 2 or phase 3 clinical trials in patients with CM. Galcanezumab is a humanized monoclonal antibody that selectively binds to and blocks the physiologic activity of CGRP. ${ }^{8}$ Patients with episodic migraine treated with galcanezumab had a significantly greater mean reduction in the number of monthly migraine headache days (MHDs) and low rates of treatment discontinuation compared with those treated with placebo. ${ }^{9-12}$ The present report includes results from the 3-month double-blind period of a phase 3 clinical trial of galcanezumab in patients with CM.

\section{Methods}

\section{Standard protocol approvals, registrations, and patient consents}

We conducted the study at 116 headache and clinical research centers in 12 countries: Argentina, Canada, Czech Republic, Germany, Israel, Italy, Mexico, the Netherlands, Spain, Taiwan, the United Kingdom, and the United States (data available from Dryad, appendix e-1, doi.org/10.5061/dryad. $8655 \mathrm{q} 79$ ). The study protocol was reviewed and approved by the appropriate institutional review board for each site and was conducted according to Good Clinical Practice and the Declaration of Helsinki guidelines. Before undergoing any study procedures, patients provided written informed consent. The first patient was enrolled in January 2016, and the last patient completed the double-blind portion of the study in March 2017. The study is registered at ClinicalTrials.gov (NCT02614261).

\section{Study design}

The study comprised 5 study periods: (1) a 3- to 45-day screening period; (2) a 1-month prospective baseline period to determine patient eligibility on the basis of daily entries into an electronic patient-reported outcomes (ePRO) diary; (3) a 3-month randomized, double-blind, placebo-controlled treatment period; (4) a 9-month open-label extension; and (5) a 4-month posttreatment period to observe the washout of the study drug. Here, we report results through the doubleblind treatment period (study period 3). Results from the openlabel and posttreatment periods will be reported separately.

\section{Patient selection}

Patients were men and women 18 to 65 years of age at screening with a diagnosis of $\mathrm{CM}$ as defined by the International Classification of Headache Disorders, 3rd edition, beta version (ICHD-3 beta) guidelines ${ }^{1}$ and migraine onset before 50 years of age. Patients had to have at least 15 headache days per month, of which at least 8 were migraine, for $>3$ months before screening and as assessed by the ePRO diary during the 1-month prospective baseline period. Patients also needed at least 1 headache-free day per month within 3 months before screening and during baseline. Patients had to be at least $80 \%$ compliant with ePRO daily diary entries and were blinded to diary eligibility criteria.

We excluded patients who had persistent daily headache, cluster headache, head or neck trauma within the past 6 months, possible posttraumatic headache, or primary headache other than CM. Patients could not have previously failed to respond to adequate trials of migraine preventives with Level A or Level B evidence from $>3$ different medication classes (based on the list of such preventives found in the American Academy of Neurology's evidence-based guidelines ${ }^{13}$ or onabotulinumtoxinA or B). Patients could not take therapeutic antibodies during or within 1 year before the study and could not have serious or unstable medical or psychiatric conditions, history of stroke, or history of substance abuse or dependence in the past year or be at risk for acute cardiovascular events based on history or ECG findings.

Patients could take acute headache medication as needed throughout the trial but could take opioid- or barbituratecontaining medications no more than 3 days per month, could not take oral corticosteroids, and could receive no more than 1 steroid injection during the study and only if in an emergency setting. Patients had to wash out all migraine preventive medications except topiramate or propranolol; patients could remain on either topiramate or propranolol if on a stable dose in the 2 months before starting the prospective baseline period and remaining on that dose throughout the baseline and double-blind periods. Patients staying on topiramate or 
propranolol were known as the concurrent migraine preventive cohort. Otherwise, patients discontinued all migraine preventives at least 30 days before entering the baseline period (or at least 4 months prior for botulinum toxin).

\section{Randomization and masking}

Eligible patients were randomized 2:1:1 to receive monthly subcutaneous injections of placebo, galcanezumab $120 \mathrm{mg}$ (with a 240-mg loading dose), or galcanezumab $240 \mathrm{mg}$ for the 3-month double-blind period. Assignment to treatment was via computer-generated random sequence with an interactive web-response system. Randomization was stratified by country, acute headache medication overuse (yes/no) as determined during prospective baseline, and presence of concurrent migraine preventive (yes/no).

To preserve blinding, patients in all treatment groups received two $1-\mathrm{mL}$ injections at each monthly dosing visit (2 placebo injections, 1 placebo and 1 galcanezumab 120 -mg injection, or 2 galcanezumab 120 -mg injections) in blinded prefilled syringes. Patients in the galcanezumab $120-\mathrm{mg}$ group received $240 \mathrm{mg}$ at their first dosing visit, followed by $120 \mathrm{mg}$ at the subsequent months. All patients had to remain in the office for a 30-minute postinjection observation period after the first dose.

\section{Study objectives and measures}

The primary objective tested the hypothesis that at least 1 dose of galcanezumab ( 120 or $240 \mathrm{mg} / \mathrm{mo}$ ) was superior to placebo in the prevention of migraine in patients with $\mathrm{CM}$ as measured by the overall mean change from baseline in the number of monthly MHDs during the 3-month double-blind treatment period. An MHD was a calendar day with a headache lasting $\geq 30$ minutes, with features meeting ICHD- 3 beta criteria for migraine or probable migraine. A headache also qualified as a migraine if the patient believed it was a migraine at onset and was relieved by a triptan or ergot. A headache day was a calendar day with any headache lasting $\geq 30$ minutes (including migraine, probable migraine, and nonmigraine headache).

Key secondary objectives compared galcanezumab with placebo on response rates (proportion of patients with $\geq 50 \%$, $\geq 75 \%$, and $100 \%$ reduction from baseline in monthly MHDs across months 1-3), mean change in functioning at month 3 measured by the Migraine-Specific Quality of Life Questionnaire (MSQ) Role Function-Restrictive score, ${ }^{14}$ overall mean reduction in monthly MHDs with acute headache medication use across months 1 to 3, and mean change in Patient Global Impression of Severity of Illness (PGI-S) ${ }^{15}$ at month 3. Other secondary objectives included comparison of galcanezumab with placebo on additional headache parameters (e.g., monthly headache days, headache hours, and migraine headache hours) across months 1 to 3, and the Migraine Disability Assessment (MIDAS) total score at month 3. ${ }^{16,17}$

Patients reported all headache information in the ePRO diary, including duration, severity, and features, as well as drug name and dose of acute headache medications taken that calendar day. Patients completed self-report scales at office visits, including the MSQ (monthly), PGI-S (monthly), and MIDAS (every 3 months). The MSQversion 2.1 assesses the effect of migraine on daily functioning in 3 domains over a 4-week recall period: Role Function-Restrictive (7 items), Role Function-Preventive (4 items), and Emotional Function (3 items). ${ }^{18}$ The MSQ items are rated on a scale of 1 to 6 , with domain scores converted to a scale of 0 to 100 such that higher scores represent better functioning. The PGI-S scale is a single-item instrument asking patients to rate the severity of their overall migraine illness on a scale of 1 (normal, not at all ill) to 7 (extremely ill). The MIDAS is a 5-item patient-rated instrument assessing number of days negatively affected by migraine during the 3-month recall period, with scores $\geq 21$ representing severe disability.

Double-blind safety assessments included adverse events (AEs) (all visits), vital signs (monthly), and weight, laboratory measures, ECGs (baseline and month 3), and treatmentemergent anti-drug antibodies (ADA; all visits). Suicidality was assessed monthly by the Columbia-Suicide Severity Scale, ${ }^{19}$ a required assessment for all investigational neurologic treatments.

\section{Statistical analysis}

The target sample size was 1,140, based on the assumption of a $15 \%$ discontinuation rate and an effect size of 0.30 in the last month of the 3-month treatment phase, to provide $\approx 95 \%$ power that at least 1 galcanezumab group would separate from placebo at a 1-sided 0.025 significance level.

We conducted analyses on all randomized patients receiving at least 1 dose of study medication. We conducted efficacy analyses on an intent-to-treat basis, with patients analyzed according to assigned treatment group. We conducted safety analyses according to patients' modal dose rather than the assigned dose. Five patients assigned to 120 -mg galcanezumab had a modal dose of $240 \mathrm{mg}$ because they discontinued after the loading dose and before the first maintenance dose.

We performed analyses of continuous repeated efficacy measures using a restricted maximum likelihood-based mixedmodels repeated-measures technique with prespecified model terms of treatment, country, acute headache medication overuse, concurrent preventive use, month, treatment $x$ month, baseline, and baseline $\times$ month. Overall mean change from baseline (i.e., the average change across months 1-3) is estimated from the model. For continuous safety and efficacy analyses with objectives evaluated at month 3 (PGI-S and MIDAS), we used an analysis of covariance model to analyze change from baseline to last-observation-carried-forward endpoint. Response rates represent the mean percentage of responders from the categorical, pseudo-likelihood-based repeated-measures analysis assessing overall response rate across months 1, 2, and 3. We used the Fisher exact test to 
analyze demographic and baseline illness characteristics. For categorical safety analyses, we used the Cochran-MantelHaenszel test for between-group comparisons, adjusting for baseline medication overuse and concurrent preventive medication use.

We adjusted for multiplicity in the primary and prespecified key secondary analyses using a superchain procedure to control for type I error. ${ }^{20}$ Hypothesis testing occurred sequentially through parallel dose branches, with the possibility to recycle available $\alpha$ as depicted in figure 1, which includes notational conventions consistent with that of previously described methods. ${ }^{20-23}$ We calculated multiplicity-adjusted $\alpha$ thresholds for each hypothesis in each step of the procedure using the appropriate multiplicity adjustment technique (the Dunnett test, ${ }^{24}$ the Hochberg procedure, ${ }^{25}$ or the Bonferroni-Holm procedure ${ }^{26}$ ). We then compared the unadjusted $p$ value for each hypothesis against its multiplicity-adjusted $\alpha$ level. We considered endpoints with an unadjusted $p$ value higher than the adjusted $\alpha$ level to be not statistically significant after multiplicity adjustment. Once we failed to reject the null hypothesis for an endpoint in the sequence (including any retesting with any available recycled $\alpha$ ), we stopped the procedure and did not test any further endpoints in the sequence for that dose branch. We automatically considered any untested endpoints in the sequence as not statistically significant after multiplicity adjustment.

We performed all statistical analyses using SAS Enterprise Guide 7.1 (SAS Institute, Cary, NC).

\section{Data availability}

Lilly makes patient-level data available from Lilly-sponsored studies on marketed drugs for approved uses after acceptance for publication. Lilly is one of several companies that provide this access through the website clinicalstudydatarequest.com. Qualified researchers can submit research proposals and request anonymized data to test new hypotheses. Lilly's datasharing policies are provided on the clinicalstudydatarequest. com site under the Study Sponsors page.

\section{Classification of evidence}

This interventional study provides Class I evidence for the primary research question, namely that both dose regimens of galcanezumab (120 mg/mo with a 240-mg loading dose and $240 \mathrm{mg} / \mathrm{mo}$ ) are superior to placebo in the reduction of the number of monthly MHDs.

\section{Results}

\section{Patient disposition}

Of 1,903 patients screened, we randomized 1,117 (figure 2). Four did not receive the study drug, leaving 1,113 in the intent-to-treat population. More than $90 \%$ of the patients in each treatment group completed the double-blind treatment period (figure 2).

\section{Patient demographics and baseline characteristics}

Demographic and baseline characteristics were generally similar across treatment groups (table 1). The galcanezumab 240-mg group had a higher percentage of patients who had

Figure 1 Multiple testing procedure

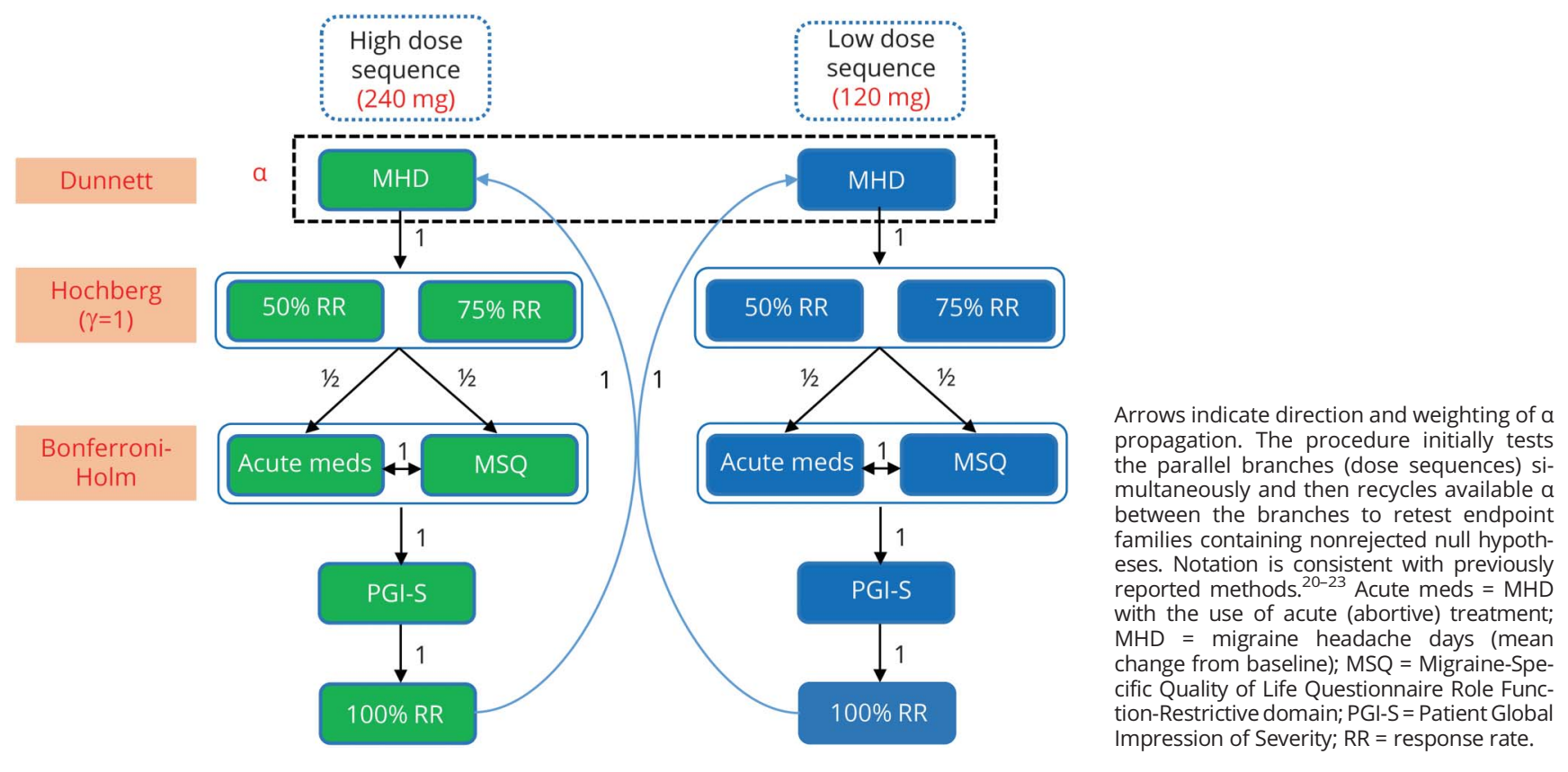




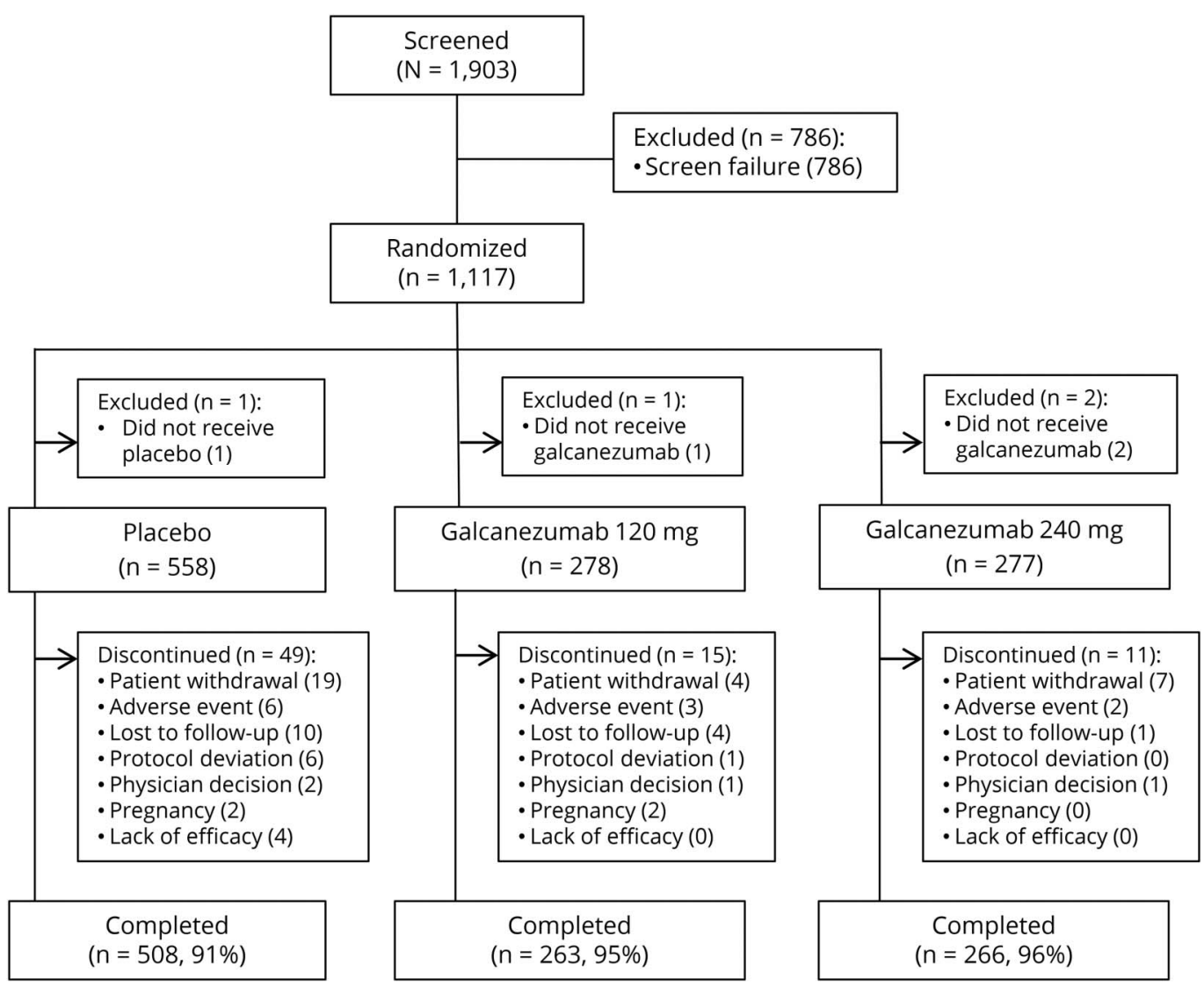

REGAIN = Evaluation of Galcanezumab in the Prevention of Chronic Migraine.

prior treatment failure of $\geq 2$ migraine preventives in the past 5 years (35\%) compared with the galcanezumab 120-mg group (24\%). There were also a few statistical differences from placebo in the galcanezumab 240-mg group, but they were not clinically meaningful. Only $15 \%$ of patients overall remained on a concurrent preventive (topiramate or propranolol) during the study.

\section{Efficacy outcomes}

On the primary endpoint, both doses of galcanezumab were superior to placebo in the overall mean reduction in the number of monthly MHDs from baseline (table 2). Monthly reductions in MHDs were statistically different from placebo for both galcanezumab doses starting with month 1 (figure 3 ). Over the 3 months of treatment, the mean percentages of patients with $\geq 50 \%$ and $\geq 75 \%$ reduction from baseline in MHDs were higher for both galcanezumab doses than for placebo ( $\geq 50 \%$ response rate: both doses $p<0.001$; $\geq 75 \%$ response rate: $120 \mathrm{mg} p<0.05,240 \mathrm{mg} p<0.001$; figure 4). After adjustment for multiplicity, galcanezumab $240 \mathrm{mg}$ demonstrated statistical improvement vs placebo on the primary and all key secondary endpoints except for $100 \%$ response rate, while galcanezumab $120 \mathrm{mg}$ had statistical improvement vs placebo on the primary endpoint and the $\geq 50 \%$ response rate (table 2 ). Results for other (nonkey) secondary measures are presented in table 2 . There were no statistical differences between doses on any efficacy measure.

\section{Safety}

There were no deaths in this study. Treatment-emergent AEs were reported by $50 \%, 58 \%$, and $57 \%$ of patients in the placebo, galcanezumab 120-mg, and galcanezumab 240-mg groups, respectively (table 3 ). Most treatment-emergent AEs were mild or moderate in severity. The most common treatment-emergent $\mathrm{AE}$ was injection-site pain, but this did not differ significantly between groups (4\% placebo, $6 \%$ galcanezumab $120 \mathrm{mg}$, 7\% galcanezumab $240 \mathrm{mg}$ ). Injection-site reaction, injection-site erythema, injection-site pruritus, and sinusitis occurred more frequently in the galcanezumab 240mg group relative to placebo, with injection-site pruritus and injection-site erythema also occurring more frequently with the $240-\mathrm{mg}$ than the $120-\mathrm{mg}$ galcanezumab dose. Six placebotreated patients discontinued as a result of AEs that included abdominal pain, alopecia, headache, migraine, and myocardial infarction. Five galcanezumab-treated patients discontinued because of an AE that included increased weight in the 120mg group and depression, increased hepatic enzymes, injection-site pain, and acute pancreatitis in the 240-mg group. 
Table 1 Patient demographics and baseline disease characteristics

\begin{tabular}{|c|c|c|c|}
\hline & \multirow[b]{2}{*}{ Placebo $(n=558)$} & \multicolumn{2}{|l|}{ Galcanezumab } \\
\hline & & $120 \mathrm{mg}(\mathrm{n}=278)$ & $240 \mathrm{mg}(\mathrm{n}=277)$ \\
\hline Age, y & $41.6(12.1)$ & $39.7(11.9)^{a}$ & $41.1(12.4)$ \\
\hline Female, n (\%) & $483(87)$ & $237(85)$ & $226(82)$ \\
\hline \multicolumn{4}{|l|}{ Race, n (\%) } \\
\hline White & $432(77)$ & $223(80)$ & $224(81)$ \\
\hline Black & $39(7)$ & $16(6)$ & $17(6)$ \\
\hline Asian & $26(5)$ & $13(5)$ & $14(5)$ \\
\hline Other & $61(11)$ & $26(9)$ & $21(8)$ \\
\hline Body mass index, kg/m² & $26.9(5.6)$ & $26.4(5.5)$ & $26.7(5.2)$ \\
\hline Migraine illness duration, y & $21.9(12.9)$ & $20.4(12.7)$ & $20.1(12.7)^{a}$ \\
\hline MHD/mo & $19.6(4.6)$ & $19.4(4.3)$ & $19.2(4.6)$ \\
\hline MHD/mo with acute medication use & $15.5(6.6)$ & $15.1(6.3)$ & $14.5(6.3)^{a}$ \\
\hline Headache $d / m o$ & $21.5(4.1)$ & $21.2(4.0)$ & $21.4(4.1)$ \\
\hline Migraine headache h/mo & $136.7(91.0)$ & $136.0(79.5)$ & $134.7(86.6)$ \\
\hline Headache h/mo & $145.1(95.1)$ & $144.7(85.4)$ & $145.9(93.4)$ \\
\hline Patient-reported aura, n (\%) & $310(56)$ & $153(55)$ & $141(51)$ \\
\hline Prior preventive treatment in past $5 \mathrm{y}, \mathrm{n}(\%)$ & $435(78)$ & $211(76)$ & $220(79)$ \\
\hline Failed $\geq 2$ preventives in past $5 y, n(\%)$ & $163(29)$ & $68(24)$ & $97(35)^{b}$ \\
\hline Acute headache medication overuse, $\mathbf{n}(\%)$ & $353(63)$ & $178(64)$ & $177(64)$ \\
\hline Concurrent preventive treatment, n (\%) & $82(15)$ & $37(13)$ & $43(16)$ \\
\hline MIDAS total score & $68.7(57.4)$ & $62.5(49.5)$ & $69.2(64.1)$ \\
\hline MSQ RF-R score & $38.4(17.2)$ & $39.3(17.3)$ & $38.9(17.3)$ \\
\hline MSQ RF-P score & $55.0(20.8)$ & $55.5(22.0)$ & $57.1(20.5)$ \\
\hline MSQ EF score & $44.2(26.0)$ & $45.3(25.8)$ & $45.7(27.4)$ \\
\hline PGI-S score & $4.9(1.2)$ & $4.8(1.2)$ & $4.9(1.3)$ \\
\hline \multicolumn{4}{|c|}{$\begin{array}{l}\text { Abbreviations: } \mathrm{EF}=\text { Emotional Function; } \mathrm{MHD}=\text { migraine headache days; MIDAS = Migraine Disability Assessment; MSQ = Migraine-Specific Quality of Life } \\
\text { Questionnaire version 2.1; PGI-S = Patient Global Impression-Severity of Illness; RF-P = Role Function-Preventive; RF-R = Role Function-Restrictive. } \\
\text { Data are mean (SD) unless otherwise indicated. } \\
\text { a } p \leq 0.05 \text { vs placebo. } \\
\text { b } p \leq 0.01 \text { vs galcanezumab } 120 \mathrm{mg} \text {. }\end{array}$} \\
\hline
\end{tabular}

There were 10 serious AEs during the study, with 4 reported in the placebo group (alcoholic pancreatitis, epistaxis, gastritis, and myocardial infarction), 1 in the galcanezumab $120-\mathrm{mg}$ group (colon cancer), and 5 in the galcanezumab 240-mg group (hypokalemia and nephrolithiasis in 1 patient, acute pancreatitis, pulmonary embolism, and renal colic).

We observed no clinically meaningful differences between galcanezumab and placebo in laboratory values, vital signs, weight, or quantitative or qualitative ECGs. Two patients in the study had a treatment-emergent abnormal hepatic enzyme: 1 in the placebo group ( 1 of 558 or $0.2 \%$ ) and 1 in the galcanezumab $240-\mathrm{mg}$ dose group (1 of 282 or $0.4 \%$ ).
Treatment-emergent suicidal ideation assessed by the Columbia-Suicide Severity Scale was reported for 4 (1\%) patients on placebo, $3(1 \%)$ patients in the galcanezumab 120 $\mathrm{mg}$ group, and 2 (1\%) patients in the galcanezumab $240-\mathrm{mg}$ group, with no suicidal behavior.

\section{Anti-drug antibodies}

During the double-blind treatment phase, treatmentemergent ADA occurred in 22 patients across the groups (1.5\%, $2.7 \%$, and $2.6 \%$ of the placebo, galcanezumab $120-\mathrm{mg}$, and galcanezumab 240-mg groups, respectively). Of these 22 patients, 13 had neutralizing ADA present (0.6\%, 2.3\%, and $1.5 \%$ of the placebo, galcanezumab $120-\mathrm{mg}$, and galcanezumab 
Table 2 Primary and secondary endpoints (time frame is across months 1 through 3 unless otherwise specified)

\begin{tabular}{|c|c|c|c|}
\hline & \multirow[b]{2}{*}{ Placebo $(n=538)$} & \multicolumn{2}{|l|}{ Galcanezumab } \\
\hline & & $120 \mathrm{mg}(\mathrm{n}=273)$ & $240 \mathrm{mg}(\mathrm{n}=274)$ \\
\hline \multicolumn{4}{|l|}{ Primary endpoint } \\
\hline Monthly MHDs & $-2.7(0.4)$ & $-4.8(0.4)$ & $-4.6(0.4)$ \\
\hline Difference $(95 \% \mathrm{Cl})$ & & $-2.1(-2.9$ to -1.3$)$ & $-1.9(-2.7$ to -1.1$)$ \\
\hline$p$ Value vs placebo ${ }^{a}$ & & $<0.001(\mathrm{~S})$ & $<0.001(\mathrm{~S})$ \\
\hline \multicolumn{4}{|l|}{ Key secondary endpoints } \\
\hline$\geq 50 \%$ response & $15.4(1.6)$ & $27.6(2.7)$ & $27.5(2.6)$ \\
\hline Odds ratio $(95 \% \mathrm{Cl})$ & & 2.1 (1.6 to 2.8$)$ & 2.1 (1.6 to 2.8$)$ \\
\hline$p$ Value vs placebo ${ }^{a}$ & & $<0.001(\mathrm{~S})$ & $<0.001(\mathrm{~S})$ \\
\hline$\geq 75 \%$ response & $4.5(0.9)$ & $7.0(1.4)$ & $8.8(1.7)$ \\
\hline Odds ratio $(95 \% \mathrm{Cl})$ & & $1.6(1.0$ to 2.5$)$ & $2.0(1.4$ to 3.1$)$ \\
\hline$p$ Value vs placebo ${ }^{a}$ & & 0.031 (NS) & $<0.001(\mathrm{~S})$ \\
\hline $100 \%$ response & $0.5(0.3)$ & $0.7(0.4)$ & $1.3(0.6)$ \\
\hline Odds ratio $(95 \% \mathrm{Cl})$ & & 1.4 (0.4 to 4.4$)$ & $2.6(1.0$ to 7.0$)$ \\
\hline$p$ Value vs placebo ${ }^{a}$ & & $0.597(\mathrm{NS})^{\mathrm{b}}$ & 0.058 (NS) \\
\hline Monthly MHDs with acute medication use & $-2.2(0.3)$ & $-4.7(0.4)$ & $-4.3(0.4)$ \\
\hline Difference $(95 \% \mathrm{CI})$ & & $-2.5(-3.3$ to -1.8$)$ & $-2.0(-2.8$ to -1.3$)$ \\
\hline$p$ Value vs placebo ${ }^{a}$ & & $<0.001(N S)^{b}$ & $<0.001(\mathrm{~S})$ \\
\hline MSQ RF-R score ${ }^{c}$ & $16.8(1.2)$ & $21.8(1.4)$ & $23.1(1.6)$ \\
\hline Difference $(95 \% \mathrm{Cl})$ & & $5.1(2.1$ to 8.0$)$ & 6.3 (3.0 to 9.6$)$ \\
\hline$p$ Value vs placebo ${ }^{a}$ & & $<0.001(\mathrm{NS})^{\mathrm{b}}$ & $<0.001$ (S) \\
\hline PGI-S score ${ }^{c}$ & $-0.6(0.1)$ & $-0.8(0.1)$ & $-0.9(0.1)$ \\
\hline Difference $(95 \% \mathrm{Cl})$ & & $-0.1(-0.3$ to 0.1$)$ & $-0.3(-0.5$ to -0.1$)$ \\
\hline$p$ Value vs placebo ${ }^{a}$ & & $0.181(N S)^{b}$ & $0.006(S)$ \\
\hline \multicolumn{4}{|l|}{ Other secondary endpoints } \\
\hline Monthly headache days & $-3.0(0.4)$ & $-4.8(0.4)$ & $-4.6(0.4)$ \\
\hline Difference $(95 \% \mathrm{Cl})$ & & $-1.8(-2.7$ to -1.0$)$ & $-1.6(-2.4$ to -0.8$)$ \\
\hline$p$ Value vs placebo ${ }^{a}$ & & $<0.001$ & $<0.001$ \\
\hline Monthly headache hours & $-13.4(3.9)$ & $-36.2(4.7)$ & $-31.5(4.7)$ \\
\hline Difference $(95 \% \mathrm{Cl})$ & & $-22.7(-31.7$ to -13.7$)$ & $-18.1(-27.1$ to -9.1$)$ \\
\hline$p$ Value vs placebo ${ }^{a}$ & & $<0.001$ & $<0.001$ \\
\hline Monthly migraine headache hours & $-14.1(3.8)$ & $-36.2(4.6)$ & $-32.1(4.6)$ \\
\hline Difference $(95 \% \mathrm{Cl})$ & & $-22.1(-30.9$ to -13.3$)$ & $-18.0(-26.8$ to -9.3$)$ \\
\hline$p$ Value vs placebo ${ }^{a}$ & & $<0.001$ & $<0.001$ \\
\hline MSQ RF-P score ${ }^{c}$ & 11.0. (1.2) & $18.0(1.4)$ & $16.1(1.4)$ \\
\hline Difference $(95 \% \mathrm{Cl})$ & & $7.0(4.2$ to 9.8$)$ & 5.1 (2.3 to 7.9$)$ \\
\hline$p$ Value vs placebo ${ }^{a}$ & & $<0.001$ & $<0.001$ \\
\hline
\end{tabular}


Table 2 Primary and secondary endpoints (time frame is across months 1 through 3 unless otherwise specified) (continued)

\begin{tabular}{|c|c|c|c|}
\hline & \multirow[b]{2}{*}{ Placebo $(n=538)$} & \multicolumn{2}{|l|}{ Galcanezumab } \\
\hline & & $120 \mathrm{mg}(\mathrm{n}=273)$ & $240 \mathrm{mg}(\mathrm{n}=274)$ \\
\hline MSQ EF score ${ }^{c}$ & $14.1(1.6)$ & $21.0(1.9)$ & $20.7(1.9)$ \\
\hline Difference $(95 \% \mathrm{Cl})$ & & 7.0 (3.2 to 10.8 ) & $6.6(2.8$ to 10.4$)$ \\
\hline$p$ Value vs placebo ${ }^{a}$ & & $<0.001$ & $<0.001$ \\
\hline MIDAS total score ${ }^{c}$ & $-11.5(3.4)$ & $-20.3(4.1)$ & $-17.0(4.1)$ \\
\hline Difference $(95 \% \mathrm{Cl})$ & & $-8.7(-16.4$ to -1.1$)$ & $-5.5(-13.1$ to 2.1$)$ \\
\hline$p$ Value vs placebo ${ }^{a}$ & & 0.025 & 0.157 \\
\hline
\end{tabular}

Abbreviations: $\mathrm{Cl}$ = confidence interval; $\mathrm{EF}=$ Emotional Function; $\mathrm{MHD}=$ migraine headache day; $\mathrm{MIDAS}=$ Migraine Disability Assessment; $\mathrm{MSQ}=\mathrm{Migraine}-$ Specific Quality of Life version 2.1; NS = not significant after multiplicity adjustment; RF-P = Role Function-Preventive; RF-R = Role Function-Restrictive; PGI-S = Patient Global Impression of Severity of Illness; S = significant after multiplicity adjustment.

Data are least-squares mean change from baseline (SE) or estimated percentage (SE) unless otherwise stated.

${ }^{a} p$ Value indicates nominal significance without multiplicity adjustment; $\mathrm{S}$ or NS indicates significant or not significant after multiplicity adjustment.

${ }^{b}$ Item not tested after all a expended on previous items in multiplicity adjustment testing sequence (figure 1). Therefore, item is considered not statistically significant regardless of $p$ value.

'Time frame is at month 3.

240-mg groups, respectively), with a statistical difference between galcanezumab $120 \mathrm{mg}$ and placebo $(p<0.05)$. Maximum ADA titers among these patients ranged from 1:20 to 1: 160. There was no discernible effect of ADA on treatment efficacy or tolerability.

\section{Discussion}

This 3-month phase 3 study met its primary objective in that both doses of galcanezumab were superior to placebo in the overall mean reduction of monthly MHDs in CM. There was no previous phase 2 study of galcanezumab in patients with CM. Patients in this study had an average of 19.3 MHDs per month and an average MIDAS score of 65.8, indicating very severe $^{27}$ disability. Monthly MHDs decreased by $\approx 5$, with a difference from placebo of 2 MHDs, representing a clinically meaningful, positive change. ${ }^{28}$ Despite the high MHD frequency and relatively short duration of the study, the percentage of patients with $\geq 50 \%$ reduction in the number of monthly MHDs was $>25 \%$ in both galcanezumab dose groups, and almost twice as many galcanezumab-treated patients had $\geq 75 \%$ reduction compared with placebo. The mean increase in functioning by 23 points on the 100-point MSQRole Function-Restrictive domain for the galcanezumab 240-mg group also represents a clinically important change; these patients with CM improved to a level of functioning more consistent with that of episodic migraine. Efficacy results appeared generally consistent with those from other

Figure 3 Reduction in MHDs at each month

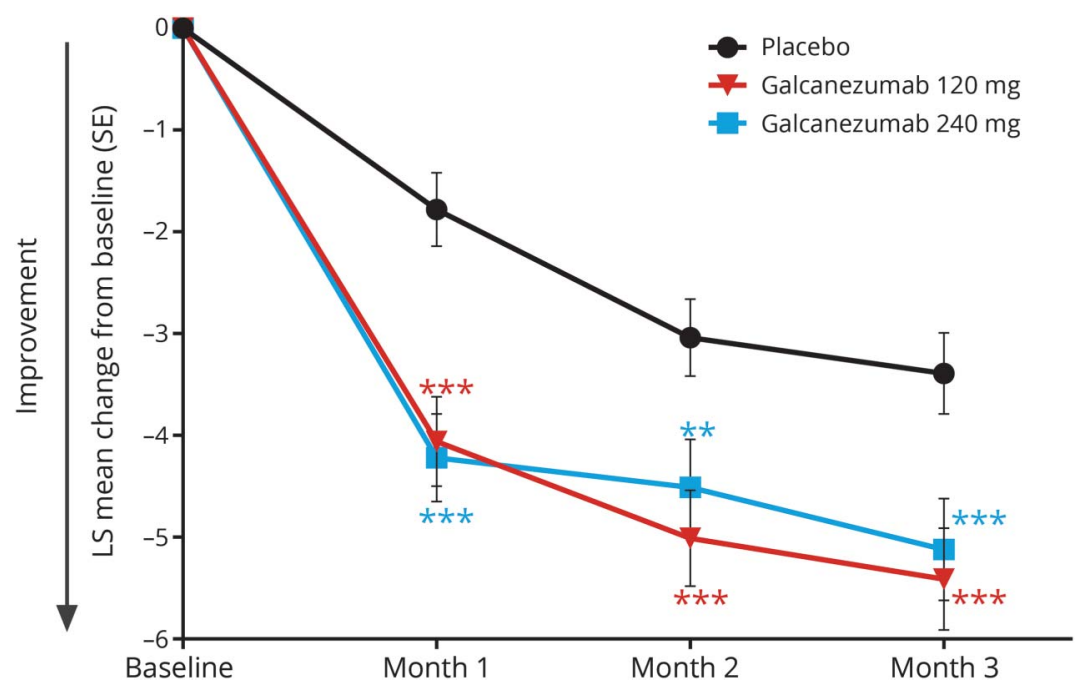

Reduction in migraine headache days (MHDs) at each month was statistically greater in both galcanezumab dose groups compared with placebo. Differences between galcanezumab doses were not significant. LS = least squares; $\mathrm{SE}=$ standard error. ${ }^{* \star *} p<0.001$ vs placebo; ${ }^{* *} p<0.01$ vs placebo. 


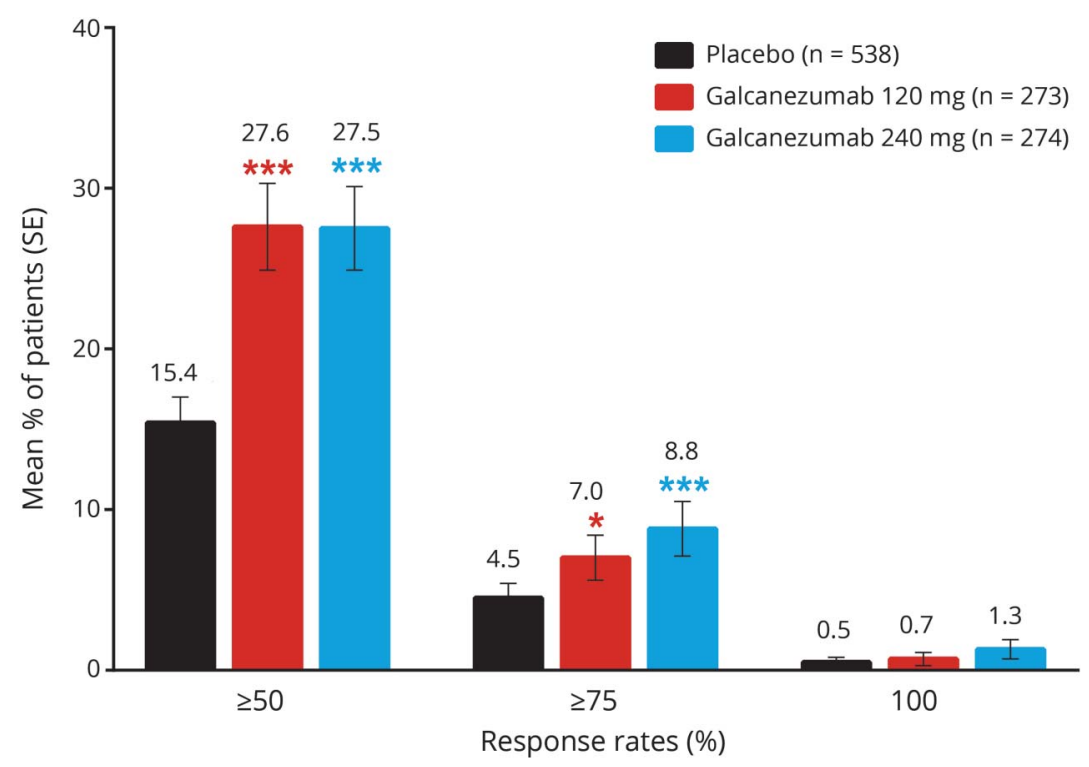

Response refers to percent reduction from baseline in monthly migraine headache days. Differences between galcanezumab doses were not significant. SE = standard error. ${ }^{* \star} p<0.001$ (statistically significant vs placebo after multiplicity adjustment); ${ }^{*}<0.05$ (not statistically significant after multiplicity adjustment). large randomized double-blind trials evaluating a preventive treatment in a $C M$ population such as those for CGRP pathway blockers, ${ }^{5-7}$ onabotulinumtoxin $A,{ }^{29,30}$ and topiramate. $^{31,32}$

In addition to efficacy, the safety and tolerability profiles are essential components in evaluating the overall therapeutic benefit of a treatment investigated in a clinical trial. ${ }^{28}$ The high rates of study completion (95\%) and low rates of discontinuation due to AEs (1\%) for the galcanezumab-treated patients suggest that galcanezumab was well tolerated, consistent with findings in the episodic migraine studies. ${ }^{11,12,33}$ Incidences of individual treatment-emergent AEs were low, with the most common being injection-site pain $(6 \%-7 \%$ across galcanezumab doses). Incidences of injection-site related treatmentemergent AEs such as injection-site reaction, injection-site erythema, and injection-site pruritus were also low but reported in a greater proportion of patients receiving galcanezumab $240 \mathrm{mg}$ compared with placebo. Most injection-site reactions were mild to moderate in severity and resolved within a few days, with no serious events. In addition, there were no clinically meaningful differences from placebo with respect to changes in laboratory parameters, vital signs, or ECGs.

Comparison of the 2 galcanezumab doses yielded few differences. Although the galcanezumab 240-mg dose met statistical significance on more key secondary endpoints after multiplicity adjustment than did the 120-mg dose, there were no statistical differences between the 2 doses on any of the efficacy measures. Together, the data suggest that the galcanezumab 120-mg dose performed as well as the galcanezumab 240-mg dose with respect to reductions in monthly MHDs, other migraine and headache parameters, and improvements in functioning and quality of life. With respect to safety and tolerability, the incidences of injection-site erythema and injection-site pruritus were higher in the galcanezumab 240-mg group than the 120-mg group. Otherwise, the 2 doses appeared quite similar.

Some limitations should be noted. Restrictions in the inclusion criteria may limit the generalizability of the results. Patients with serious and unstable medical conditions were excluded, as were patients who had demonstrated significant treatmentresistance to multiple previous migraine preventive medications. In addition, the 3-month duration of the study, while sufficient to demonstrate efficacy, may not be long enough to demonstrate the ultimate effects of the treatment; here, analysis of the 9-month open-label extension may help. Nevertheless, further study is needed to evaluate both the benefits and risks of long-term use of galcanezumab in the CM patient population.

This phase 3 trial of galcanezumab for prevention of CM demonstrated that both doses of galcanezumab were efficacious, safe, and well tolerated after treatment for up to 3 months. These findings contribute further support that the CGRP pathway inhibition is a biologically specific, diseasetargeted approach to the prevention of migraine that offers an important advance in the management of a common and disabling neurologic disease.

\section{Author contributions}

Dr. Detke contributed to the study design, interpretation of data, and creating/revising the content. Dr. Goadsby contributed to the interpretation of data and revised the manuscript for content. Dr. Wang contributed to the analyses of data and study design and revised the manuscript for content. Dr. Friedman, Dr. Selzler, and Dr. Aurora revised the manuscript for content. 
Table 3 Treatment-emergent AEs that occurred in $\geq 2 \%$ of galcanezumab-treated patients treated with either dose of galcanezumab and greater than placebo

\begin{tabular}{|c|c|c|c|}
\hline \multirow[b]{2}{*}{ AE } & \multirow[b]{2}{*}{ Placebo $(n=558), n(\%)$} & \multicolumn{2}{|c|}{ Galcanezumab, n (\%) } \\
\hline & & $120 \mathrm{mg}(\mathrm{n}=273)$ & $240 \mathrm{mg}(\mathrm{n}=282)$ \\
\hline Patients with $\geq 1$ events & $279(50)$ & $159(58)^{a}$ & $160(57)$ \\
\hline Injection-site pain & $24(4)$ & $17(6)$ & $20(7)$ \\
\hline Nasopharyngitis & $26(5)$ & $17(6)$ & $9(3)$ \\
\hline Upper respiratory tract infection & $13(2)$ & $9(3)$ & $9(3)$ \\
\hline Injection-site reaction & $10(2)$ & $8(3)$ & $15(5)^{\mathrm{b}}$ \\
\hline Injection-site erythema & $5(1)$ & $4(1)$ & $13(5)^{c, d}$ \\
\hline Fatigue & $10(2)$ & $6(2)$ & $6(2)$ \\
\hline Back pain & $14(3)$ & $9(3)$ & $2(1)^{d}$ \\
\hline Urinary tract infection & $7(1)$ & $6(2)$ & $4(1)$ \\
\hline Abdominal pain & $9(2)$ & $6(2)$ & $4(1)$ \\
\hline Diarrhea & $9(2)$ & $3(1)$ & $6(2)$ \\
\hline Injection-site pruritus & $1(0)$ & $0(0)$ & $7(2)^{b, d}$ \\
\hline Migraine & $5(1)$ & $5(2)$ & $4(1)$ \\
\hline Influenza-like illness & $3(1)$ & $5(2)$ & $4(1)$ \\
\hline Neck pain & $8(1)$ & $7(3)$ & $0(0)^{a, d}$ \\
\hline Oropharyngeal pain & $3(1)$ & $2(1)$ & $5(2)$ \\
\hline Sinusitis & $5(1)$ & $4(1)$ & $8(3)^{a}$ \\
\hline Arthralgia & $5(1)$ & $1(0)$ & $5(2)$ \\
\hline Pyrexia & $2(0)$ & $5(2)^{a}$ & $1(0)$ \\
\hline
\end{tabular}

Abbreviation: $\mathrm{AE}=$ adverse event.

a $p<0.05$ vs placebo.

${ }^{\mathrm{b}} p<0.01$ vs placebo.

c $p<0.001$ vs placebo.

d $p<0.05$ vs galcanezumab $120 \mathrm{mg}$.

\section{Acknowledgment}

The authors thank all of the study participants, site investigators, and personnel involved in the Evaluation of Galcanezumab in the Prevention of Chronic Migraine (REGAIN) study. They also thank Vladimir Skljarevski, $\mathrm{MD}$, Brian Millen, $\mathrm{PhD}$, and Jyun Yan Yang, MD, for their contributions during the study and Jonna Ahl, $\mathrm{PhD}$, for assistance in drafting the manuscript.

\section{Study funding}

Study was funded by Eli Lilly and Company. This work has been reported previously at the American Headache Society and International Headache Society meetings in 2017.

\section{Disclosure}

$\mathrm{H}$. Detke is a full-time employee and minor shareholder of Eli Lilly and Company. P. Goadsby reports grants from Eli Lilly and Company; personal fees from Alder BioPharmaceuticals, Dr Reddy's Laboratories, Electrocore LLC, Novartis, Pfizer
Inc, Scion, Teva Pharmaceuticals, medicolegal work, Journal Watch, Up-to-Date, Oxford University Press, Massachusetts Medical Society, and Wolters Kluwer; grants and personal fees from Allergan, Amgen, and eNeura Inc; and other from Trigemina Inc. In addition, Dr. Goadsby has a patent for magnetic stimulation for headache licensed to eNeura without fee. S. Wang is a full-time employee and minor shareholder of Eli Lilly and Company. D. Friedman reports speaker fees from Allergan; advisory board and speaker fees from Supernus and Amgen; advisory board, consultant, and speaker fees from Avanir; advisory board fees from Alder BioPharmaceuticals and Biohaven Pharmaceuticals; consultant and advisory board fees from electroCore; advisory board and grant support from Teva and Zosano; grant support and consultant fees from Eli Lilly and Company; and grant support from Merck, Autonomic Technologies, Inc, and Axon Optics. D. Friedman has been a consultant for Promius, serves on editorial board for Neurology Reviews, and is a contributing author to MedLink Neurology. K. Selzler and S. Aurora are full-time employees 
and minor shareholders of Eli Lilly and Company. Go to Neurology.org/ $\mathrm{N}$ for full disclosures.

\section{Publication history}

Received by Neurology February 28, 2018. Accepted in final form August 9, 2018.

\section{References}

1. Headache Classification Committee of the International Headache Society. The International Classification of Headache Disorders, 3rd edition (beta version). Cephalalgia 2013;33:629-808.

2. Buse DC, Manack A, Serrano D, Turkel C, Lipton RB. Sociodemographic and comorbidity profiles of chronic migraine and episodic migraine sufferers. J Neurol Neurosurg Psychiatry 2010;81:428-432.

3. Bigal ME, Lipton RB. Migraine chronification. Curr Neurol Neurosci Rep 2011;11: 139-148.

4. Ho TW, Edvinsson L, Goadsby PJ. CGRP and its receptors provide new insights into migraine pathophysiology. Nat Rev Neurol 2010;6:573-582.

5. Smith J, Dodick DW, Goadsby PJ, Silberstein SD, Lipton RB, Hirman J. Randomized, double-blind, placebo-controlled trial of ALD403 (eptinezumab), an anti-CGRP monoclonal antibody for the prevention of chronic migraine: 59th Annual Scientific Meeting American Headache Society ${ }^{\otimes}$ June 8-11, 2017 Westin Boston Waterfront Boston, MA. Headache 2017;57:130.

6. Silberstein SD, Aycardi E, Bigal ME, et al. Fremanezumab for chronic migraine preventive treatment. N Engl J Med 2017;377:2113-2122.

7. Tepper S, Ashina M, Reuter U, et al. Safety and efficacy of erenumab for preventive treatment of chronic migraine: a randomised, double-blind, placebo-controlled phase 2 trial. Lancet Neurol 2017;16:425-434.

8. Vermeersch S, Benschop RJ, Van Hecken A, et al. Translational pharmacodynamics of calcitonin gene-related peptide monoclonal antibody LY2951742 in a capsaicininduced dermal blood flow model. J Pharmacol Exp Ther 2015;354:350-357.

9. Dodick DW, Goadsby PJ, Spierings ELH, Scherer JC, Sweeney SP, Grayzel DS. Safety and efficacy of LY2951742, a monoclonal antibody to calcitonin gene-related peptide, for the prevention of migraine: a phase 2, randomised, double-blind, placebo-controlled study. Lancet Neurol 2014;13:885-892.

10. Skljarevski V, Oakes TM, Zhang $\mathrm{Q}$ et al. Galcanezumab for episodic migraine prevention: a randomized phase $2 \mathrm{~b}$ placebo-controlled dose-ranging clinical trial. JAMA Neurol 2018;75:187-193.

11. Stauffer VL, Dodick DW, Zhang Q, Carter JN, Ailani J, Conley RR. Evaluation of galcanezumab for the prevention of episodic migraine: the EVOLVE-1 randomized clinical trial. JAMA Neurol 2018;75:1080-1088.

12. Skljarevski V, Matharu M, Millen BA, Ossipov MH, Kim BK, Yang JY. Efficacy and safety of galcanezumab for the prevention of episodic migraine: results of the EVOLVE-2 phase 3 randomized controlled clinical trial. Cephalalgia 2018;38:1442-1454

13. Silberstein SD, Holland S, Freitag F, Dodick DW, Argoff C, Ashman E. Evidencebased guideline update: pharmacologic treatment for episodic migraine prevention in adults. Neurology 2012;78:1337-1345.

14. Jhingran P, Osterhaus JT, Miller DW, Lee JT, Kirchdoerfer L. Development and validation of the Migraine-Specific Quality of Life Questionnaire. Headache 1998;38: 295-302.
15. Guy W. ECDEU Assessment Manual for Psychopharmacology, Revised 1976 Rockville: National Institute of Mental Health, Psychopharmacology Research Branch:217-222. Available at: archive.org/details/ecdeuassessmentm1933guyw. Accessed January 24, 2017.

16. Stewart WF, Lipton RB, Kolodner K, Liberman J, Sawyer J. Reliability of the Migraine Disability Assessment Score in a population-based sample of headache sufferers. Cephalalgia 1999;19:107-114.

17. Stewart WF, Lipton RB, Dowson AJ, Sawyer J. Development and testing of the Migraine Disability Assessment (MIDAS) Questionnaire to assess headache-related disability. Neurology 2001;56(suppl 1):S20-S28.

18. Rendas-Baum R, Bloudek LM, Maglinte GA, Varon SF. The psychometric properties of the Migraine-Specific Quality of Life Questionnaire version 2.1 (MSQ) in chronic migraine patients. Qual Life Res 2013;22:1123-1133.

19. Posner K, Brown GK, Stanley B, et al. The Columbia-Suicide Severity Rating Scale: initial validity and internal consistency findings from three multisite studies with adolescents and adults. Am J Psychiatry 2011;168(12): $1266-1277$.

20. Kordzakhia G, Dmitrienko A. Superchain procedures in clinical trials with multiple objectives. Stat Med 2013;32:486-508

21. Millen BA, Dmitrienko A. Chain procedures: a class of flexible closed testing procedures with clinical trial applications. Stat Biopharmaceut Res 2011;3:14-30.

22. Bretz F, Maurer W, Brannath W, Posch M. A graphical approach to sequentially rejective multiple test procedures. Stat Med 2009;28:586-604.

23. Dmitrienko A, Wiens BL, Tamhane AC, Wang X. Tree-structured gatekeeping tests in clinical trials with hierarchically ordered multiple objectives. Stat Med 2007;26: $2465-2478$

24. Dunnett CW. A multiple comparison procedure for comparing several treatments with a control. J Am Stat Assoc 1955;50:1096-1121.

25. Hochberg Y. A sharper Bonferroni procedure for multiple tests of significance. Biometrika 1988;75:800-802.

26. Holm S. A simple sequentially rejective multiple test procedure. Scand J Stat 1979;6: $65-70$.

27. Blumenfeld AM, Varon SF, Wilcox TK, et al. Disability, HRQoL and resource use among chronic and episodic migraineurs: results from the International Burden of Migraine Study (IBMS). Cephalalgia 2011;31:301-315.

28. Dodick DW, Turkel CC, DeGryse RE, et al. Assessing clinically meaningful treatment effects in controlled trials: chronic migraine as an example. J Pain 2015; 16:164-175.

29. Aurora SK, Dodick DW, Turkel CC, et al. OnabotulinumtoxinA for treatment of chronic migraine: results from the double-blind, randomized, placebo-controlled phase of the PREEMPT 1 trial. Cephalalgia 2010;30:793-803.

30. Diener HC, Dodick DW, Aurora SK, et al. OnabotulinumtoxinA for treatment of chronic migraine: results from the double-blind, randomized, placebo-controlled phase of the PREEMPT 2 trial. Cephalalgia 2010;30:804-814.

31. Silberstein SD, Lipton RB, Dodick DW, et al. Efficacy and safety of topiramate for the treatment of chronic migraine: a randomized, double-blind, placebo-controlled trial. Headache 2007;47:170-180.

32. Diener HC, Bussone G, Van Oene JC, Lahaye M, Schwalen S, Goadsby PJ. Topiramate reduces headache days in chronic migraine: a randomized, double-blind, placebo-controlled study. Cephalalgia 2007;27:814-823.

33. Oakes TM, Skljarevski V, Zhang Q, et al. Safety of galcanezumab in patients with episodic migraine: a randomized placebo-controlled dose-ranging phase $2 \mathrm{~b}$ study. Cephalalgia 2018;38:1015-1025. 


\section{Neurology}

\section{Galcanezumab in chronic migraine: The randomized, double-blind, placebo-controlled REGAIN study}

Holland C. Detke, Peter J. Goadsby, Shufang Wang, et al.

Neurology 2018;91;e2211-e2221 Published Online before print November 16, 2018

DOI 10.1212/WNL.0000000000006640

This information is current as of November 16, 2018

Updated Information \&

Services

References

Citations

Subspecialty Collections

Permissions \& Licensing

Reprints including high resolution figures, can be found at: http://n.neurology.org/content/91/24/e2211.full

This article cites 32 articles, 4 of which you can access for free at: http://n.neurology.org/content/91/24/e2211.full\#ref-list-1

This article has been cited by 4 HighWire-hosted articles: http://n.neurology.org/content/91/24/e2211.full\#\#otherarticles

This article, along with others on similar topics, appears in the following collection(s):

Class I

http://n.neurology.org/cgi/collection/class_1

Clinical trials Randomized controlled (CONSORT agreement)

http://n.neurology.org/cgi/collection/clinical_trials_randomized_contro

lled_consort_agreement

Migraine

http://n.neurology.org/cgi/collection/migraine

Patient safety

http://n.neurology.org/cgi/collection/patient_safety

Quality of life

http://n.neurology.org/cgi/collection/quality_of_life

Information about reproducing this article in parts (figures,tables) or in its entirety can be found online at:

http://www.neurology.org/about/about_the_journal\#permissions

Information about ordering reprints can be found online:

http://n.neurology.org/subscribers/advertise

Neurology ${ }^{\circledR}$ is the official journal of the American Academy of Neurology. Published continuously since 1951, it is now a weekly with 48 issues per year. Copyright Copyright ( 2018 The Author(s). Published by Wolters Kluwer Health, Inc. on behalf of the American Academy of Neurology.. All rights reserved. Print ISSN: 0028-3878. Online ISSN: 1526-632X.

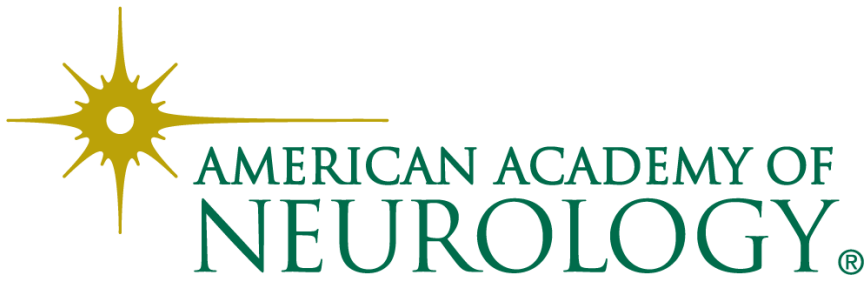

